\title{
COMPARATIVE STUDY OF ORAL CLONIDINE WITH ORAL DIAZEPAM AS PREMEDICATION IN PATIENTS FOR GENERAL ANAESTHESIA
}

\author{
Yathish Nanjaiah ${ }^{1}$, Moses Charles Dsouzaㄹ, Rahul Fernandez ${ }^{3}$ Sumithra Selvam ${ }^{4}$
}

${ }_{1}^{1}$ Assistant Professor, Department of Anaesthesiology, Sanjay Gandhi Institute of Trauma and Orthopaedics, Bangalore, Karnataka, India.

2Professor, Department of Anaesthesiology and Critical Care, St. John's Medical College Hospital, Bangalore, Karnataka, India. 3Senior Resident, Department of Anaesthesiology and Critical Care, St. John's Medical College Hospital, Bangalore, Karnataka, India. ${ }^{4}$ Senior Resident, Division of Biostatistics, St. John's Research Institute, Bangalore, Karnataka, India.

\section{ABSTRACT}

\section{BACKGROUND}

The sequence of induction of anaesthesia, laryngoscopy and tracheal intubation is associated with marked haemodynamic changes and autonomic reflex activity which may be a cause of concern in many high-risk patients. Objective of this study is to compare the effects of oral Clonidine with Diazepam with respect to anxiolysis, sedation, anaesthetic requirements, heart rate, blood pre ssure, attenuation of sympathetic responses to laryngoscopy and intubation, respiratory rate and undesirable effects.

\section{MATERIALS AND METHODS}

100 ASA I and II status normotensive patients scheduled for elective surgical procedure were selected randomly and divided into two groups of 50 each. Group I received $3 \mu \mathrm{gm} / \mathrm{kg}$ oral Clonidine and Group II received oral Diazepam $10 \mathrm{mg}$, $90 \mathrm{minutes}$ before induction of anaesthesia. Anxiolysis, sedation, anti-sialagogue effect, respiratory rate, heart rate, systolic and diastolic pressure were recorded during premedication and 90 minutes after premedication. Also, the HR, systolic, diastolic blood pressures were recorded non-invasively during induction, 1, 3, 5, 10, 15, 30 minutes from the onset of laryngoscopy. Also, the dose of thiopentone injected intravenously till the loss of eyelash reflex was calculated and any undesirable effects were looked for.

\section{RESULTS}

After premedication with oral Clonidine $3 \mu \mathrm{gm} / \mathrm{kg}$ BW, heart rate, diastolic blood pressure, respiratory rate were equally comparable to oral Diazepam, however systolic blood pressure decreased in the Clonidine group and also the dose of Inj. Thiopentone was less in Clonidine group. After intubation, the incidence of tachycardia was significantly greater in the Diazepam group than in Clonidine group. Rise in SBP and DBP were also statistically significant in Diazepam group than in Clonidine group.

\section{CONCLUSION}

Clonidine provides better anxiolysis without any change in the respiratory pattern when compared with Diazepam group. Oral Clonidine $3 \mu \mathrm{gm} / \mathrm{kg}$ provides a consistent, reliable and effective attenuation of pressor response as compared to Diazepam $10 \mathrm{mg}$.

\section{KEY WORDS}

Clonidine; Diazepam; Attenuation; Pressor Response; Laryngoscopy; Premedication; Anxiolysis; Sedation; Anti-Sialagogue.

HOW TO CITE THIS ARTICLE: Nanjaiah Y, Dsouza MC, Fernandez R, et al. Comparative study of oral clonidine with oral diazepam as premedication in patients for general anaesthesia. J. Evolution Med. Dent. Sci. 2018;7(52):5560-5564, DOI: $10.14260 /$ jemds/2018/1230

\section{BACKGROUND}

Anxiety is a normal emotional response to the impending surgery. Premedication controls anxiety, postoperative pain, nausea and vomiting and reduces the risk of aspiration during induction of anaesthesia. Preanaesthetic medication forms an integral part of anaesthetic management and some form of premedication is universally administered before any anaesthesia. An ideal premedicant should be effective and pleasant to be taken orally, should produce sedation, ease of separation and facilitate smooth induction of anaesthesia, should have anti-sialagogue effect, have analgesia and non

'Financial or Other Competing Interest': None.

Submission 24-11-2018, Peer Review 09-12-2018,

Acceptance 11-12-2018, Published 24-12-2018.

Corresponding Author:

Dr. Moses Charles Dsouza,

Professor,

Department of Anaesthesiology \& Critical Care,

St. John's Medical College Hospital,

Sarjapur Road, Bangalore- 560034, Karnataka, India

E-mail: drmosescharlesdsouza@gmail.com

DOI: $10.14260 /$ jemds $/ 2018 / 1230$ stability or depress respiration and should reduce the requirement of anaesthetic drugs.

Alpha-2 adrenoceptor agonists have been used as premedicants because of their beneficial properties in anaesthesia. Clonidine is now commonly used for its antihypertensive and negative chronotropic effects but has many properties of an ideal premedicant and also beneficial effects on haemodynamics during stressful conditions like laryngoscopy and endotracheal intubation. During general anaesthesia Clonidine reportedly enhances intraoperative circulatory stability by reducing catecholamine levels.

This study was done to evaluate the effectiveness of oral Clonidine in attenuating the hemodynamic responses associated with laryngoscopy and endotracheal intubation and its effect was compared with commonly used premedicant diazepam. The aims and objectives of this study was to compare the premedication effects of oral Clonidine with oral diazepam with respect to anxiety, sedation, heart rate, blood pressure, dose of anaesthetic requirements, sympathetic responses to laryngoscopy and intubation, and respiratory rate. 


\section{MATERIALS AND METHODS}

This randomized controlled trial study was conducted in tertiary care teaching Hospital after ethical committee approval. After written informed consent from all the patients, 100 patients belonging to "American Society of Anesthesiologists" (ASA) GRADE I and II, Physical status aged between 18 to 56 years, scheduled for elective Orthopaedic, Otorhinolaryngology, Gynaecological and general surgeries were included in the study. Unwilling Patients, emergency Surgeries, patients with ASA Grade III or higher, patients with Neurological and endocrine abnormalities, renal impairment, hepatic disease, congestive heart failure, valvular heart disease, Hypotension, Ischemic heart disease, diabetes mellitus, patients on Psychotropic drugs or history of drug allergies were excluded from the study.

Sample size was estimated based on the study done by Chattopadhyay $\mathrm{S}$ et.al. ${ }^{1}$ In order to observe a minimum difference of 4 BPM on heart rate immediately after ET Tube Insertion with standard deviation of 4.08 and 7.01 in study groups 1 and group 2 with 1\% level of significance (Adjusted for Multiple Comparison) and $80 \%$ power, the number of subjects required in each group was 47 , we have considered recruiting 50 patients in each group, totally 100 patients.

A computer-generated randomization list was prepared using online software to randomize patients into group I and group II. 100 patients were randomly allocated into two groups with 50 patients in each group.

\section{Group I}

All patients in this group received oral tablet Clonidine 3 $\mu \mathrm{gm} / \mathrm{kg}$ body weight 90 minutes before surgery.

\section{Group II}

All the patients in this group received oral tablet Diazepam $10 \mathrm{mg}$, 90 minutes before surgery.

Pre-anaesthetic checkup was done prior to the surgery. Patients were evaluated for systemic diseases and routine laboratory investigations recorded. On the day of surgery, systolic and diastolic blood pressures, heart rate and respiratory rate were measured before premedication and scoring was done for sedation, anxiolysis and anti-sialagogue effects 90 minutes after premedication.

Other side effects like hypotension, bradycardia, vomiting were evaluated.

Following Scoring Systems were used-

\begin{tabular}{|c|c|}
\hline Degree of Sedation & Score \\
\hline Asleep & 3 \\
\hline Moderately Drowsy & 2 \\
\hline Mild Drowsiness & 1 \\
\hline Awake & 0 \\
\hline Sedation Scoring (4-point scale) \\
\hline
\end{tabular}

\begin{tabular}{|c|c|}
\hline Degree of Anxiety & Score \\
\hline Quiet or Comfortable & 4 \\
\hline Uneasy & 3 \\
\hline Anxious & 2 \\
\hline Very Upset or Worried & 1 \\
\hline Frightened or Terrified & 0 \\
\hline Anxiety Scoring (5-Point Scale) \\
\hline
\end{tabular}

\begin{tabular}{|c|c|}
\hline Degree of Dryness & Score \\
\hline Dry mouth & 2 \\
\hline Moist & 1 \\
\hline Wet & 0 \\
\hline Anti-Sialagogue Effect Scoring (3-Point Scale) \\
\hline
\end{tabular}

Antisialagogue effect was scored by checking drying of mouth with a blotting paper by blotting the tongue and inner aspect of cheek for 30 seconds each.

After the above assessment, an 18G intravenous cannula was inserted and infusion of lactated Ringers solution was given. Patients were connected to the cardiac monitor for recording the ECG in lead II. NIBP Cuff was connected to measure the blood pressure non-invasively. Baseline recording of heart rate and arterial pressure was done.

All the patients were pre-oxygenated with $100 \%$ oxygen for 3 minutes before induction with a tight-fitting face mask. Patients were induced with Inj. Thiopentone sodium $2.5 \%$ and administered slowly till the loss of eyelash reflex. Injection Glycopyrrolate $0.2 \mathrm{mg}$ IV was given prior to thiopentone. Intermediate acting neuromuscular blocking agent Inj. Vecuronium was given as muscle relaxant. Laryngoscopy was done using rigid laryngoscope with standard Macintosh blade. Intubation was done with appropriately sized disposable, high volume low pressure cuffed endotracheal tube. The patients were then ventilated with $60 \%$ nitrous oxide and $40 \%$ oxygen with a tidal volume of $10-12 \mathrm{ml} / \mathrm{kg}$ and a rate of $12-14$ breaths per minute. Systolic, diastolic blood pressures and heart rate were monitored during induction and at one, three, five, ten, fifteen and thirty minutes after intubation of the trachea. At the end of the surgery, patient was extubated after reversal of nondepolarizing muscle relaxant with Inj. Neostigmine 0.05 $\mathrm{mg} / \mathrm{kg}$ IV and Inj. Glycopyrrolate $0.01 \mathrm{mg} / \mathrm{kg}$ IV.

An observation was made related to adverse effects of drugs and anaesthesia related problems and were attended to appropriately.

\section{Statistical Methods}

Descriptive statistical analysis has been carried using mean with SD for the continuous measurements and number and \% for the categorical measurements. Independent $t$ test was used to test the significance of study parameters on continuous scale between two groups. Chi-square test was used to test the association between study parameters with study groups. Repeated measures ANOVA was carried out to assess the time and interaction effect (time $\mathrm{x}$ group) between study groups on vital parameters adjusted for sex. Probability value less than $5 \%$ was considered statistically significant. All the analyses were carried using SPSS version 23.0.

\section{RESULTS}

There was no significant difference between the two groups with respect to age, weight and significant difference in the sex with male being higher in Group II (Table 1) was seen. Degree of sedation, anti-sialagogue effect and respiratory rate were comparable between the two groups studied (Table 2-3). Table 3 shows that, in group I, the minimum dosage of Inj. Thiopentone that required for loss of eyelash reflex or induction was $150 \mathrm{mg}$ and a maximum of $250 \mathrm{mg}$ 
with a mean of $187.5 \pm 28.2$. In Group II, the minimum dosage of Inj. Thiopentone that required for loss of eyelash reflex or induction was $150 \mathrm{mg}$ and a maximum of $300 \mathrm{mg}$ with a mean of $236.0 \pm 31.6$. The requirement of Inj. Thiopentone for Induction between two groups was significantly higher in Group II as compared to Group I ( $\mathrm{p}<0.001)$.

\begin{tabular}{|c|c|c|c|}
\hline & Group I & Group II & P value \\
\hline Age in Years & $36.70 \pm 11.21$ & $36.00 \pm 10.39$ & 0.747 \\
\hline Sex & $21(42.0)$ & $33(66.0)$ & 0.016 \\
Male & $29(58.0)$ & $17(34.0)$ & \\
Female & $49.82 \pm 6.13$ & $50.66 \pm 6.71$ & 0.515 \\
\hline Weight & Table 1. Comparison of Baseline Characteristics between \\
Group I and II \\
\hline
\end{tabular}

Mean \pm SD; number (\%);

\begin{tabular}{|c|c|c|c|}
\hline & Group I & Group II & P value \\
\hline \multicolumn{4}{|l|}{ Degree of Sedation } \\
\hline 0 & $15(30.0)$ & $16(32.0)$ & \multirow{4}{*}{0.685} \\
\hline 1 & $11(22.0)$ & $14(28.0)$ & \\
\hline 2 & $24(48.0)$ & $20(40.0)$ & \\
\hline 3 & 0 & 0 & \\
\hline \multicolumn{4}{|l|}{ Anxiolysis Score } \\
\hline 0 & - & $4(8.0)$ & \multirow{5}{*}{$<0.0001$} \\
\hline 1 & - & $10(20.0)$ & \\
\hline 2 & - & $26(52.0)$ & \\
\hline 3 & $16(32.0)$ & $10(20.0)$ & \\
\hline 4 & $34(68.0)$ & 0 & \\
\hline \multicolumn{4}{|l|}{ Anti Sialagogue Score } \\
\hline 0 & $4(8.0)$ & 0 & \multirow{3}{*}{0.123} \\
\hline 1 & $24(48.0)$ & $27(54.0)$ & \\
\hline 2 & $22(44.0)$ & $23(46.0)$ & \\
\hline \multicolumn{4}{|c|}{$\begin{array}{l}\text { Table 2. Comparison of Clinical Characteristics between } \\
\text { Group I and II }\end{array}$} \\
\hline
\end{tabular}

\begin{tabular}{|c|c|c|c|}
\hline & Group I & Group II & $P$ value \\
\hline $\begin{array}{l}\text { Respiratory Rate } \\
\text { (Breaths/min) } \\
\text { Before medication } \\
\text { After medication }\end{array}$ & $\begin{array}{l}14.42 \pm 0.91 \\
14.34 \pm 0.77\end{array}$ & $\begin{array}{l}14.54 \pm 0.99 \\
14.46 \pm 0.81\end{array}$ & $\begin{array}{l}0.529 \\
0.451\end{array}$ \\
\hline $\begin{array}{l}\text { Dosage of Inj. } \\
\text { Thiopentone (mg) }\end{array}$ & $187.5 \pm 28.2$ & $236.0 \pm 31.6$ & $<0.001$ \\
\hline
\end{tabular}

Table 3. Comparison of Respiratory Rate and Dosage of Inj. Mean \pm SD;

$$
\text { Thiopentone between the Two Groups Studied }
$$

\begin{tabular}{|c|c|c|c|c|c|c|}
\hline & \multicolumn{2}{|c|}{\begin{tabular}{|c} 
Heart Rate \\
(beats/min)§
\end{tabular}} & \multicolumn{2}{|c|}{$\begin{array}{c}\text { SBP } \\
(\mathrm{mmHg})^{\S}\end{array}$} & \multicolumn{2}{|c|}{$\begin{array}{c}\text { DBP } \\
(\mathrm{mmHg})^{\S}\end{array}$} \\
\hline & $\underset{\text { I }}{\text { Group }}$ & $\begin{array}{c}\text { Group } \\
\text { II }\end{array}$ & $\begin{array}{c}\text { Group } \\
\text { I }\end{array}$ & $\begin{array}{c}\text { Group } \\
\text { II }\end{array}$ & $\underset{\text { I }}{\text { Group }}$ & $\begin{array}{c}\text { Group } \\
\text { II }\end{array}$ \\
\hline Pre-op & $\begin{array}{c}72.6 \pm \\
6.3 \\
\end{array}$ & \begin{tabular}{|c|}
$74.7 \pm$ \\
7.8 \\
\end{tabular} & $\begin{array}{c}115.0 \pm \\
9.5\end{array}$ & $\begin{array}{c}118 \pm \\
13.8 \\
\end{array}$ & $\begin{array}{c}79.1 \pm \\
7.6 \\
\end{array}$ & $\begin{array}{c}79.9 \pm \\
7.6\end{array}$ \\
\hline Induction & $\begin{array}{c}74.1 \pm \\
6.6\end{array}$ & $\begin{array}{c}76.2 \pm \\
7.3 \\
\end{array}$ & $\begin{array}{c}107.4 \pm \\
9.5\end{array}$ & $\begin{array}{c}120.3 \pm \\
15.6\end{array}$ & $\begin{array}{c}79.2 \pm \\
8.2\end{array}$ & $\begin{array}{c}80.7 \pm \\
7.9\end{array}$ \\
\hline $1^{\prime} \mathrm{M}^{*}$ & $\begin{array}{c}85.2 \pm \\
7.6\end{array}$ & $\begin{array}{c}107.8 \pm \\
11\end{array}$ & $\begin{array}{c}127.2 \pm \\
9.2\end{array}$ & $\begin{array}{c}154.8 \pm \\
10.1\end{array}$ & $\begin{array}{c}88 \pm \\
7.1\end{array}$ & $\begin{array}{c}97.2 \pm \\
5.7\end{array}$ \\
\hline $3^{\prime} \mathrm{M}^{*}$ & $\begin{array}{c}82.8 \pm \\
7.3\end{array}$ & $\begin{array}{c}104.4 \pm \\
9.9\end{array}$ & $\begin{array}{c}123.2 \pm \\
10\end{array}$ & $\begin{array}{c}147.3 \pm \\
8.2\end{array}$ & $\begin{array}{c}86 \pm \\
6.9\end{array}$ & $\begin{array}{c}80.7 \pm \\
7.9\end{array}$ \\
\hline $5^{\prime} \mathrm{M}^{*}$ & $\begin{array}{c}80.9 \pm \\
6.9\end{array}$ & $\begin{array}{c}99.9 \pm \\
7.8\end{array}$ & $\begin{array}{c}120.3 \pm \\
10.3\end{array}$ & $140 \pm 9.6$ & $\begin{array}{c}83.5 \pm \\
7.4\end{array}$ & $\begin{array}{c}90.1 \pm \\
6.0\end{array}$ \\
\hline $10^{\prime} \mathrm{M}^{*}$ & $\begin{array}{l}78.1 \\
\pm 6.7 \\
\end{array}$ & $\begin{array}{c}96.5 \pm \\
6.6\end{array}$ & $\begin{array}{c}118.0 \pm \\
10.2\end{array}$ & $\begin{array}{c}134.4 \pm \\
9.5\end{array}$ & $\begin{array}{c}81.1 \pm \\
7.4\end{array}$ & $\begin{array}{c}87.9 \pm \\
6.0\end{array}$ \\
\hline $15^{\prime} \mathrm{M}^{*}$ & $\begin{array}{l}76.4 \\
\pm 6.3 \\
\end{array}$ & $\begin{array}{c}92.2 \pm \\
7.8\end{array}$ & $\begin{array}{c}115.40 \pm \\
9.4\end{array}$ & $\begin{array}{c}127.6 \pm \\
9.5\end{array}$ & $\begin{array}{l}80.6 \\
\pm 7.5\end{array}$ & $\begin{array}{c}85.5 \pm \\
6.4\end{array}$ \\
\hline $30^{\prime} \mathrm{M}^{*}$ & $\begin{array}{c}75.4 \pm \\
6.3\end{array}$ & $\begin{array}{l}89.0 \\
+7.2\end{array}$ & $\begin{array}{c}113.7 \pm \\
9.0\end{array}$ & $124 \pm 9.5$ & $\begin{array}{c}79.9 \pm \\
7.5\end{array}$ & $\begin{array}{c}83.9 \pm \\
7.0\end{array}$ \\
\hline
\end{tabular}

Table 4. Comparison of Heart rate, SBP and DBP between the Two Groups of Patients Studied

Reported as mean \pm SD; *-heart rate, SBP and DBP are significantly different between group I and group II from 1 'M till 30'M except pre-op and induction; §-RMANOVA was also carried out; time effect- $\mathrm{p}<0.0001$; interaction groups effect $\mathrm{p}<0.0001$;

Number (\%);

\begin{tabular}{|c|c|c|c|c|c|c|}
\hline & \multicolumn{2}{|c|}{ HR } & \multicolumn{2}{c|}{ SBP } & \multicolumn{2}{c|}{ DBP } \\
\hline & Group I & Group II & Group I & Group II & Group I & Group II \\
\hline \multirow{2}{*}{ Pre-Op and Induction } & $1.5 \pm 1.7$ & $1.5 \pm 2.3$ & $7.7 \pm 5.6$ & $2.2 \pm 8.1$ & $0.12 \pm 2.3$ & $0.8 \pm 2.5$ \\
& $2.1 \%$ & $2.0 \%$ & $-6.7 \%$ & $1.9 \%^{*}$ & $0.2 \%$ & $1.0 \%$ \\
\hline \multirow{2}{*}{ Induction to 1 min } & $11.2 \pm 4.7$ & $31.6 \pm 10.6$ & $19.9 \pm 7.0$ & $34.4 \pm 16.9$ & $8.8 \pm 4.1$ & $16.4 \pm 6.4$ \\
& $15.1 \%$ & $42.3 \%^{*}$ & 18.55 & $28.6 \%^{*}$ & $11.1 \%$ & $20.3 \%^{*}$ \\
\hline \multirow{2}{*}{$3 \min$} & $8.7 \pm 5.7$ & $28.2 \pm 0.7$ & $15.8 \pm 7.5$ & $27.0 \pm 14.6$ & $6.8 \pm 4.6$ & $12.4 \pm 6.5$ \\
& $11.7 \%$ & $34.7 \%^{*}$ & $14.7 \%$ & $22.4 \%^{*}$ & $8.6 \%$ & $15.4 \%^{*}$ \\
\hline \multirow{2}{*}{$5 \mathrm{~min}$} & $6.8 \pm 5.2$ & $23.7 \pm 9.9$ & $12.9 \pm 7.1$ & $19.6 \pm 14.1$ & $4.3 \pm 5.1$ & $9.4 \pm 6.5$ \\
& $9.2 \%$ & $31.7 \%^{*}$ & $12.0 \%$ & $16.3 \%^{*}$ & $5.4 \%$ & $11.6 \%^{*}$ \\
\hline \multirow{2}{*}{$10 \mathrm{~min}$} & $4.0 \pm 4.6$ & $20.3 \pm 9.7$ & $10.6 \pm 6.9$ & $14.0 \pm 14.7$ & $1.8 \pm 5.4$ & $7.2 \pm 6.5$ \\
& $5.4 \%$ & $27.2 \%^{*}$ & $9.9 \%$ & $11.6 \%$ & $2.3 \%$ & $8.9 \%^{*}$ \\
\hline \multirow{2}{*}{$15 \mathrm{~min}$} & $2.3 \pm 3.3$ & $16.0 \pm 0.4$ & $8.0 \pm 6.4$ & $7.3 \pm 12.2$ & $1.4 \pm 4.2$ & $4.8 \pm 5.2$ \\
& $3.1 \%$ & $21.4 \%^{*}$ & $7.4 \%$ & $6.1 \%$ & $1.8 \%$ & $5.9 \%^{*}$ \\
\hline \multirow{2}{*}{$30 \mathrm{~min}$} & $1.2 \pm 2.5$ & $12.8 \pm 9.7$ & $6.3 \pm 5.3$ & $3.6 \pm 10.4$ & $0.6 \pm 3.7$ & $3.2 \pm 4.9$ \\
& $1.3 \%$ & $17.1 \%^{*}$ & $5.9 \%$ & $3.0 \%$ & $0.7 \%$ & $4.0 \%{ }^{*}$ \\
\hline
\end{tabular}

Table 5. Comparisons between Group I and Group II to find the increase in HR, SBP and DBP from pre-induction to post laryngoscopy

Reported as mean \pm SD; \% change; ${ }^{*}$ - p $<0.05$; significantly different between group I and group II;

Analysis of heart rate showed that there was a significant time and interaction effect $(\mathrm{p}<0.001)$ (Table 4) even after adjusted for sex. Overall there was a significant change in the Heart Rate in both groups, however the change was significantly higher in Diazepam (Group II) group as compared to Clonidine (Group I). Heart rate significantly increased from $1^{\prime} \mathrm{M}$ to $3^{\prime} \mathrm{M}$, then started decreasing from $5^{\prime} \mathrm{M}$ which was higher in Group II as compared to group I being 
non-significant from pre-op to induction between groups. Maximum increase in heart rate is $15.1 \%$ in Clonidine group (Group I) and 42.3\% in Diazepam group (Group II) which was statistically significant $(\mathrm{p}<0.001)$ (Table 5). These differences in heart rate between Clonidine group and Diazepam group remains statistically highly significant at all times except pre-op to induction. Maximum increase in heart rate in Clonidine group was $15.1 \%$ at 1 -minute post laryngoscopy which was far less than the Diazepam group $(42.3 \%)$ increases in heart rate were clinically significant until the end of $10 \mathrm{~min}$ in Clonidine group and clinically significant in all time in Diazepam group. There was no significant difference in heart rates before premedication and during induction ( 90 minutes after premedication between Clonidine and Diazepam groups $(\mathrm{p}<0.05)$.

The heart rate response between Clonidine and Diazepam was significant starting from pre-op to 15 minutes $(\mathrm{p}<0.001)$ and pre-op to $30 \mathrm{~min}$, where it is significant with Clonidine showing a favourable response towards attenuation of heart rate.

Similarly, analysis of systolic and diastolic blood pressure results showed that there was a significant time and interaction effect (time $x$ group) $(\mathrm{p}<0.0001)$ (Table 4) even after adjusted for sex. Significant variation noted in Clonidine and Diazepam groups in systolic blood pressure before and 90 minutes after premedication. A rise of systolic blood pressure by $18.5 \%$ was observed in Clonidine group as compared to $28.6 \%$ in Diazepam group which is statistically significant $(\mathrm{p}<0.001)$ (Table 5). Clonidine group showed a better attenuation compared to Diazepam group in systolic blood pressure until 5 minutes post laryngoscopy. Immediately post laryngoscopy at 1 minute, the difference was significant $(\mathrm{p}<0.001)$. Also, analysis of diastolic Blood Pressure shows maximum rise $11.1 \%$ in Clonidine group and a rise of $20.3 \%$ were noted in Diazepam groups following 1' min post laryngoscopy (Table 5). Attenuation of diastolic blood pressure by Clonidine as compared to Diazepam group was statistically significant until 30 minutes $(p<0.001)$.

\section{DISCUSSION}

Premedication before anaesthesia is considered as important stage in the process of anaesthesia. The goals are to produce anxiolysis, sedation, analgesia, ant sialagogue effect and reduces post operative nausea and vomiting. There is a search still on for an ideal premedicant which fulfils most of the goals without increasing adverse effects

Clonidine though primary an antihypertensive has been increasingly used as premedication ${ }^{2.3 .4}$ since it reduces anaesthetic requirements, improves hemodynamic stability especially during laryngoscopy and intubations, and also potentiates post operative analgesic regimens.

In our study the sedation scores was comparable with the study done by Chaurasia SK et al 5 found statistically insignificant difference between the two groups of clonidine and diazepam \& atropine groups. Raval DL et $\mathrm{al}^{6}$ found in their study that oral Clonidine showed better sedation in comparison to Diazepam which produced less sedation. The sedative action of Clonidine may be due to decreased tonic activity of the locus coeruleus, which modulates the stimuli arriving at the central nervous system.

In our study the anxiolysis score was found to be highly significant between the two groups $(\mathrm{p}<0.001)$. Our study showed better anxiolysis scores in Clonidine group than the Diazepam group which means that patients in the Clonidine group were more comfortable compared to the Diazepam group. Chaurasia SK et $\mathrm{al}^{5}$ in their study observed better anxiolytic properties in Clonidine group than the diazepam \& atropine group. Wright PMC et al7 in his study showed significant reduction in anxiety with Clonidine group when compared to the inert group.

The anti-sialagogue effect was assessed on a 3-point scale prior to induction of anaesthesia. In our study both the groups showed similar anti-sialagogue effect. This was compared with the studies done by Chaurasia SK et al. ${ }^{5}$ Showing similar anti-sialagogue effect in both the groups of Clonidine and Diazepam atropine group. Raval et al. ${ }^{6}$ Showed better anti-sialagogue effect in Clonidine group comparable to Diazepam group. Regarding dosage of thiopentone, Clonidine has been found to reduce the sleep dose of Thiopentone and the MAC values of inhalation anaesthetics. In our study, Clonidine produced a significant reduction in the sleep dose of Inj. Thiopentone as compared to Diazepam. Similar findings were observed by Wright PMC et al7 in 1990 who observed reduction in the sleep dose of methohexitone after Clonidine premedication.

In our study, there was no change in the respiratory rate in both the groups. These findings were similar to a study done by Raval DL et al. ${ }^{6}$ who showed no statistically significant decrease in respiratory rate 90 mins after premedication in either clonidine gor diazepam group.

In our study, there was no significant change in the heart rates during the premedication and 90 minutes after premedication between the two groups, however heart rate increased by a maximum of $15.1 \%$ in Clonidine group when compared to $42.3 \%$ in the Diazepam group at 1 minute following laryngoscopy and intubation. Clonidine group attenuated the heart rate significantly $(\mathrm{p}<0.001)$. It reaches a value which is clinically less significant by the end of 30 minutes in Clonidine while remaining on a higher range in the Diazepam group even after 30 minutes. Attenuation of maximum rise in the heart rate by Clonidine is evident and statistically highly significant when compared with Diazepam group ( $p<0.001$ ). A similar finding was found in a study done by Roy $\mathrm{S}$ et $\mathrm{al}^{8}$ and $\mathrm{R}$ Brindha et $\mathrm{al}^{9}$ that Clonidine was highly significant in the attenuation of maximum rise in the heart rate when compared to Diazepam. Chattopadhyay $\mathrm{S}$ et al study showed that clonidine attenuated heart rate effectively. Even study done by Chaurasia SK et al ${ }^{5}$ showed similar findings that Clonidine was a better drug to attenuate rise in heart rate comparing it to a combination of Diazepam and atropine.

In our study, the Clonidine group systolic blood pressure reduced by $6.7 \%, 90$ minutes after premedication but there was no change in the Diazepam group. It increased maximally after 1 minute from onset of laryngoscopy and intubation. It gradually decreased to preinduction value over 10-15 minutes. With Diazepam group, the maximum rise in systolic blood pressure was $28.6 \%$ above the preoperative values (During premedication) at 1 minute did not come to baseline even after 30 minutes following laryngoscopy and intubation. Similar attenuation of sympathoadrenal response to laryngoscopy and intubation was observed by Pouttu et al. ${ }^{4}$ Clonidine showed a better drug to attenuate rise in systolic blood pressure comparing it to Diazepam $(\mathrm{p}<0.001)$. 
In our study maximal rise in diastolic blood pressure was $11.1 \%$ in Clonidine group and in Diazepam group it was $20.3 \%(\mathrm{p}<0.001)$. In Clonidine group, the diastolic blood pressure almost reached the baseline by the end of 10-15 minutes following laryngoscopy and intubation while it remained high even after 30 minutes following laryngoscopy and intubation $(\mathrm{p}<0.001)$ in the Diazepam group. Similar attenuation of sympathoadrenal response to laryngoscopy and intubation was observed by Pouttu et $\mathrm{al}^{4}$ and Chaurasia SK et al. 5

None of the patients in both groups suffered from bradycardia and hypotension in our study. The effect of Clonidine on the hemodynamic responses may be attributable to its overall inhibitory action on the catecholaminergic areas of the lower brain, as stated by Aho M, et al10 in 1990.

\section{CONCLUSION}

Premedication with oral Clonidine $3 \mu \mathrm{gm} / \mathrm{kg}$ body weight, given 90 minutes prior to surgery provides better anxiolysis, reduces anaesthetic requirement and attenuates sympathetic responses to laryngoscopy and intubation, when compared to oral Diazepam $10 \mathrm{mg}$ given as premedication 90 minutes prior to surgery.

\section{REFERENCES}

[1] Chattopadhyay S, Pal RK, Mitra M, et al. Study of the role of oral clonidine premedication on haemodynamic changes during laparoscopic cholecystectomy under general anaesthesia with endotracheal intubation. J Evolution Med Dent Sci 2016;5(54):3586-91.

[2] Benhamou D, Veillette Y, Narchi P, et al. Ventilatory effects of premedication with Clonidine. Anaesth Analg 1991;73(6):799-803.
[3] Filos KS, Patroni O, Goudas LC, et al. A dose response study of orally administered Clonidine as premedication in elderly: evaluating hemodynamic safety. Anesth Analg 1993;77(6):1185-92.

[4] Pouttu J, Scheinin B, Rosenberg PH, et al. Oral premedication with Clonidine: effects on stress response during general anaesthesia. Acta Anaesthesiol Scand 1987;31(8):730-4.

[5] Chaurasia SK, Kane DG, Chaudhari L, et al. A comparative study of Clonidine versus a combination of Diazepam and atropine for premedication in orthopaedic patients. J Postgrad Med 1999;45(3):74-8.

[6] Raval DL, Mehta MK, et al. Oral Clonidine premedication for attenuation of hemodynamic response to laryngoscopy and intubation. Ind J Anaesth 2002;46(2):124-9.

[7] Wright PMC, Carabine UA, McClune S, et al. Pre anaesthetic medication with Clonidine. Br J Anaesth 1990;65(5):628-32.

[8] Roy S, Gupta RA, Mondal T, et al. Attenuation of cardiovascular responses to laryngoscopy and tracheal intubation with oral Clonidine. (Arkamine) Ind J Anesth 1993;41:62-6.

[9] Brindha R, Jayanthi K, Shankar R, et al. A Comparison of oral Clonidine versus oral Diazepam premedication for maintaining haemodynamic stability during craniotomy. Indian Journal of Clinical Anaesthesia 2016;3(3):446-50.

[10] Aho M, Lehtinen AM, Laatikainen T, et al. Effects of intramuscular Clonidine on hemodynamic and plasma $\beta$ - endorphin responses to gynecologic laparoscopy. Anesthesiology 1990;72(5):797-802. 